\title{
Geopolítica do conhecimento e descolonização epistemológica em Darcy Ribeiro
}

\author{
Adélia Miglievich-ribeiro - Universidade Federal do Espírito Santo (UFES) \\ Edison Romera Jr - Universidade Federal do Espírito Santo (UFES)
}

\begin{abstract}
Resumo
O artigo apresenta a proposta darcyniana de descolonização epistemológica mediante a eleição da América Latina como 'lugar de enunciação' e a afirmação de uma antropologia descentralizada. Darcy Ribeiro expõe uma 'história alternativa da humanidade' que rompe com a concepção eurocentrada vigente e abre novas possibilidades de compreensão do desenvolvimento histórico. Ao se tornar 'cidadão latino-americano', no exílio iniciado em 1964, seu pensamento desafia a geopolítica mundial do conhecimento e antecipa o atual 'giro descolonial'. Em sua biografia, o cientista não se dissocia do homem político que explica a persistência do subdesenvolvimento do 'Terceiro Mundo' - coetânea à prosperidade do 'Primeiro Mundo" - e luta pelo direito dos 'subalternos' narrarem sua própria história.
\end{abstract}

Palavras-chave:

Darcy Ribeiro; geopolítica do conhecimento; América Latina; descolonização epistemológica.

\section{The Geopolitics of knowledge and the epistemic decolonization in Darcy Ribeiro}

\begin{abstract}
:
This paper presents the Darcynian proposal of epistemic decolonization throughout the selection of Latin America as "locus of enunciation" and the affirmation of a decentralized anthropology. Darcy Ribeiro exposes an "alternative history of humanity" that renounces the Eurocentric conception in place and raises new possibilities for the comprehension of historical development. By becoming a "Latin-American citizen", while in exile that started in 1964, his thinking challenges the global geopolitics of knowledge and forecasts the current "decolonial shift". In his biography, the scientist does not dissociate from the political man that explains the persistency of the underdevelopment of the "Third World", coexisting with the prosperity of the "First World", and the fight for the rights of the subaltern to narrate their own history.
\end{abstract}

Keywords:

Darcy Ribeiro; geopolitics of knowledge; Latin America; epistemic decolonization.

\section{Geopolítica do conhecimento e descolonização epistemológica em Darcy Ribeiro}

\section{Introdução}

Falamos de descolonização epistemológica quando nos impomos a tarefa de desmontar e evidenciar os 'transplantes teóricos' presentes na construção do conhecimento a partir das periferias. Convencidos de que saber implica julgar, vemos como o discurso científico pode ser silenciador de vozes a depender de seu uso. 
Sem invalidar a ciência in toten, mas atentando para suas consequências, buscamos discutir como Darcy Ribeiro (1922-1997) pôde constatar o quanto a explicação hegemônica acerca do subdesenvolvimento do chamado 'Terceiro Mundo' levava à sua permanência nesse estágio e limitava drasticamente as chances de seus povos se fazerem sujeitos de sua própria história. Uma 'armadilha intelectual', se assim puder ser nomeada, mantinha nos brasileiros em geral a ideologia de que eram eles inferiores em relação aos países do Norte. Dos saraus acadêmicos às ruas, o povo brasileiro é tido como ‘culpado’ por suas próprias mazelas, repetindo-se até hoje, nos diagnósticos das agências e bancos transnacionais, a 'sentença condenatória', recordando o intelectual Manoel Bomfim (1868-1932), acerca da inviabilidade da nação brasileira.

Impressionado positivamente com América Latina. Males de Origem (1993) de Bomfim, cuja edição de 1993 prefacia, Darcy indaga por que o original pensador sergipano é ainda subestimado. Encontra a resposta no fato de que este, embora tendo estudado em Paris, dentre outros centros, ousou contrariar as teses de seu tempo que reincidiam em atribuir ao clima, à raça, ao catolicismo, o 'atraso' do Brasil. Ao contrário, Manoel Bomfim apontou para as instituições ‘colonialismo' e 'escravidão' como as responsáveis pela pobreza da população brasileira submetida a uma elite tirânica e corrupta. Recusando-se ser um mero reprodutor de teses alheias que inferiorizavam, por princípio, as especificidades da realidade brasileira (e latino-americana, num sentido mais amplo), Manoel Bomfim inspira com seu traço de autonomia o pensamento de Darcy Ribeiro.

Darcy estava consciente de sua condição subalterna na geopolítica do conhecimento. Sabia do quão incomum era propor uma teoria geral a partir de um lócus que não o Primeiro Mundo que, por sua vez, vê o resto do mundo como objeto, jamais sujeito. Mas o antropólogo brasileiro se proclama sujeito e "é precisamente no interior dessa tensão que a observação de Darcy Ribeiro adquire sua densidade, uma tensão entre a situação descrita e o local do sujeito no interior da situação que está descrevendo" (MIGNOLO, 2003, p. 36). Desconstruir a ideia de primeiro ou terceiro mundos é duvidar da ideologia que projetou a Europa e a América do Norte como centro e aferidor hierárquico (DUSSEL, 2010) de todas e quaisquer experiências históricas. Carlos PortoGonçalves (2005) propõe a reflexão:

É como se houvesse um saber atópico, um saber-de-lugar-nenhum, que se quer universal, e capaz de dizer quais saberes são locais ou regionais. Assim como cada um, de cada lugar do mundo, tem de assinalar em seu endereço eletrônico o país onde mora e de onde fala - .br (Brasil) ou .ve (Venezuela); ou .mx (México) ou .cu (Cuba) ou .ar (Argentina) ou .co (Colômbia) - aquele que fala a partir dos EUA não precisa por .us ao seu endereço e, assim, é como se falasse de lugarnenhum, tornando familiar que cada qual se veja, sempre, de um lugar 
determinado, enquanto haveria aqueles que falam como se fossem do mundo e não de nenhuma parte especifica. [...] E a melhor dominação, sabemos, é aquela que, naturalizada, não aparece como tal (PORTO-GONÇALVES, 2005, p. 9.).

Para Walter Mignolo (2001), o horizonte pedagógico estabelecido pela hierarquia epistêmica colonial na modernidade é caracterizado, dentre outros, pela língua nacional e pelo lugar hierárquico que ocupam os idiomas na estrutura epistêmica de poder. A partir do século XIX, a própria organização das ciências sociais resultou na radical assertiva de que "as línguas adequadas para as ciências sociais foram, principalmente, o francês, o inglês e o alemão" (MIGNOLO, 2001, p. 176. Tradução nossa). O eurocentrismo impõe, assim, a colonialidade do saber que define o que é ou não um conhecimento válido.

Darcy Ribeiro elabora, então, seu pensamento rebelde e trazê-lo é reforçar o imperativo da descolonização epistemológica hoje. Dissertar, a partir dele, acerca da geopolítica do conhecimento e da afirmação da América Latina como lugar de enunciação de saberes legítimos é nosso propósito.

\section{Darcy Ribeiro: o descolonizador}

Filho da professora Josefina Augusta da Silveira, mais conhecida por Mestra Fininha e de Reginaldo Ribeiro dos Santos, um pequeno empresário industrial, Darcy Ribeiro nasceu em 26 de outubro de 1922, em Montes Claros, pequena cidade do norte de Minas Gerais. Morreria, após uma vida de excepcionais realizações, em 17 de fevereiro de 1997, no Hospital Sarah Kubitschek, em Brasília, com 74 anos de idade. Deixava a sensação naqueles que pessoalmente o conheceram, e com ele compartilharam a amizade, que "tudo que fez e viveu, parece pouco, mínimo, para o que foi feito e vivido" (NEPOMUCENO, 2009, p. 11).

Darcy Ribeiro perdeu o pai precocemente em idade que ainda não lhe era possível retê-lo na memória. Viveu com sua mãe na casa de seus avós maternos. Por vontade de sua mãe, e desejo compartilhado por seu tio, Plínio Ribeiro, ingressou na Faculdade de Medicina, na capital Belo Horizonte, em 1939. A filiação ao Partido Comunista, em 1940, realizou uma guinada em seus interesses. Conta que passaram a ser os problemas sociais brasileiros e sua superação o que perseguia obstinadamente, nos três anos consecutivos em que, ainda matriculado na Faculdade de Medicina, caía no rendimento mínimo exigido, e submergia nos cursos vários das faculdades de Filosofia, Letras, Direito, dentre outras. Em 1943, tornou-se nítida sua escolha de modo que abandonou a Medicina, convicto de sua vocação para as Ciências Sociais. Tendo conhecido o professor e sociólogo Donald Pierson, seguiu para a cidade de São Paulo, ingressando na Escola Livre de Sociologia e Política (ELSP) ${ }^{1}$. Graduou-se em 1946, sendo, posteriormente, reconhecido 
como um de seus alunos mais ilustres dada a contribuição ímpar à pesquisa sociológica e antropológica na 'redescoberta' do Brasil (KANTOR et. al., 2009).

Após formado, recusou a entrada imediata no Mestrado, optando por trabalhar no Serviço de Proteção aos Índios (SPI). Quem o auxiliou a efetivar esta oportunidade de emprego, foi seu professor Herbert Baldus, de origem alemã e que viveu no Brasil por quase toda sua vida. Baldus, à época, já tendo escrito sua mais importante obra etnológica, referência para os estudiosos da área, havia sido responsável por mais de uma década pelo Seminário de Etnologia Brasileira, frequentado por Darcy Ribeiro durante os três anos de sua graduação na ELSP. Acerca do professor, o então jovem antropólogo atesta: “Aprendi muito com Baldus. Aprendi sobretudo a fazer meu seu ideal científico de estudar a natureza humana pela observação dos modos de ser, de viver e de pensar dos índios do Brasil”" (RIBEIRO, 1997, p. 126). Baldus recomendou em carta Darcy Ribeiro para General Rondon, à frente do SPI, que, por sua vez, solicitou ao então Ministro da Agricultura, Daniel de Carvalho, que o contratasse como 'naturalista', a única nomenclatura existente para designar etnólogos, botânicos, zoólogos ou geólogos que realizavam expedições científicas. Inicialmente sua escolha foi recebida com estranhamento e mesmo, com rejeição, tanto por familiares quanto por, e principalmente, seus amigos e colegas acadêmicos.

É curioso que, segundo Darcy Ribeiro, a substituição do ingresso quase automático no mestrado da ELSP em prol da experiência nas aldeias indígenas espantara os colegas e, talvez, alguns professores: "todos rechaçavam, às vezes indignados [...] dizendo que eu era uma espécie de bright young man, capaz de vencer em qualquer campo, perguntavam por que eu fazia o que lhes parecia um suicídio, metendo-me na selva, com os índios" (RIBEIRO, 1990, p. 39). Darcy Ribeiro, contudo, mais consciente ou menos, optava, em verdade, por conhecer, de dentro, o Brasil.

Fiz uma pesquisa de dois anos nos anos 50 entre os índios Urubu-Kaapor [...] eram os índios mais próximos dos Tupinambá que viviam na costa em 1500. Mas, em 500 anos, a língua deles mudou, os hábitos deles mudaram e eles são outros, mas são outros muito próximos, os mais próximos. Então Eu me treinei para outra coisa: para ir ler na realidade" (GRUPIONI; GRUPIONI, 1997, p. 27).

Assim, participou de expedições científicas e conviveu entre as populações indígenas dos Terenas, Kaingang, Xokleng, Ofayé-Xavante, Guarani, Kaiowá-Guarani, Kadiwéu, Bororo, Xavante, Carajás, Xinguanos, Guajajara, Tembé, Krêjê e Urubu-Ka'apor. Chegou à direção do SPI e, dentre a série de iniciativas em favor das causas indígenas, estavam a fundação do Parque Nacional Indígena do Xingu, em 1952, e a criação, na cidade do Rio de Janeiro, em 1953, do Museu do Índio que passou a abrigar, a partir de 1955, a primeira pós-graduação em Antropologia do Brasil, voltada para a formação de quadros especializados em pesquisas etnológicas (GOMES, 
2000). Darcy Ribeiro obteve o reconhecimento de 'precursor' da etnologia brasileira (CORRÊA, 1988a, 1988b; OLIVEIRA, 1997, 2003; OLIVEIRA, 1995; GOMES, 2000, LARAIA, 1997; MATTOS, 2007) e um dos principais teóricos a formular teses acerca da presença das populações indígenas no processo de formação nacional.

O encontro de Darcy Ribeiro com a educação teve lugar nos anos 1950, quando conheceu Charles Wagley no SPI. Antropólogo norte-americano, um dos pioneiros do ensino da disciplina no Brasil, trabalhara com Anísio Teixeira no Centro Brasileiro de Pesquisas Educacionais (CBPE), e cuidou de aproximar ambos. Darcy Ribeiro reconheceu no educador e homem público Anísio Teixeira o mestre com quem se aliaria dali em diante e em caráter definitivo na luta em defesa da educação pública, laica, gratuita e de qualidade no país. Convidado por este para dirigir o CBPE, por sua vez, subordinado ao Instituto Nacional de Estudos Pedagógicos (Inep), presidido por Anísio e vinculado ao Ministério da Educação e Cultura (MEC), aceitou o novo desafio.

Na direção do CBPE, na capital Rio de Janeiro, a primeira iniciativa de Darcy Ribeiro foi arregimentar uma equipe interna de cientistas sociais e colaboradores externos ${ }^{2}$ a fim de viabilizar um triplo programa de estudos e pesquisas a contemplar: a) pesquisas de campo em municípios, zonas urbana e rural, representativos da diversidade brasileira; b) pesquisa bibliográfica e interdisciplinar de sistematização dos estudos e teses acerca da formação brasileira; c) pesquisas sociológicas sobre os processos de industrialização e urbanização (RIBEIRO, 1990, p. 115). Para tal propósito, promoveu a criação de centros regionais de pesquisa e de experimentação que pudessem subsidiar a elaboração de políticas educacionais desde o ponto de vista da diversidade nacional.

Em 1959, Juscelino Kubitschek nomeou Anísio Teixeira responsável pela construção da rede pública de educação básica do novo distrito federal. Ciente, Darcy Ribeiro expôs a seu mentor a necessidade de se pensar em caráter de urgência também uma universidade para Brasília. Tal ideia, por meio de Anísio Teixeira, começou a ressoar no poder central. O apoio da Sociedade Brasileira para o Progresso da Ciência (SBPC) a Darcy Ribeiro garantiu a autonomia de seu planejamento. Por fim, as adesões de Cyro dos Anjos e de Victor Nunes Leal, respectivamente, Subchefe e Chefe da Casa Civil de JK, também, as presenças de Lúcio Costa e Oscar Niemeyer, encarregados do projeto físico da universidade, levaram o Presidente da República a nomear Darcy Ribeiro, Cyro dos Anjos e Oscar Niemeyer responsáveis pela criação da UnB.

João Goulart, na condição de Primeiro Ministro no curto parlamentarismo brasileiro, assinou a Lei 3.998, criando a Fundação Universidade de Brasília, em 15 de dezembro de 1961. A UnB começou a funcionar quatro meses depois, tendo Darcy Ribeiro e Anísio Teixeira, respectivamente, como reitor e vice-reitor. Em 1962, Darcy Ribeiro foi encarregado, por Jango, 


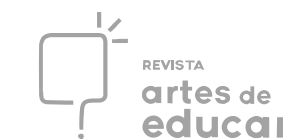

de ser seu Ministro da Educação, tendo Anísio Teixeira assumido a Reitoria. Pouco tempo depois, quando da reinstalação do presidencialismo no Brasil, tornou-se chefe do Gabinete Civil da Presidência da República, até o Golpe Militar de 1964. Imediatamente, a UnB sofreu as consequências de uma repressão crescente até ter seu projeto interrompido ${ }^{3}$.

Darcy Ribeiro, no exílio, teve seu nome vinculado às principais experiências de renovação universitária a partir da reflexão pioneira contida na UnB. Tornou-se, podemos dizer, um consultor indispensável para os governos progressistas que também ambicionavam a construção de um sistema educacional não subserviente aos ditames daqueles a quem interessava o subdesenvolvimento de seus povos. Dentre outros, colaborou com a Universidade da República Oriental do Uruguai, de 1964 a 1968, com a Universidade Central da Venezuela, entre 1969 e 1970, com a Universidade do Chile, em 1970 e 1971, com os sistemas universitários da Argélia, no ano de 1972, na África, e do Peru, em 1973. Darcy elaborou, também, o projeto básico de implantação da Universidade Nacional da Costa Rica e ofereceu para a Universidade Autônoma do México o plano de sua Faculdade de Educação e Comunicação (RIBEIRO, 2010).

Seu exílio equivaleu a 12 anos de intensa produção intelectual e realizações no campo político-cultural-educacional, redefinindo seu núcleo inicial de ideias sobre a 'universidade necessária' para a 'aceleração evolutiva', em antagonismo ao modelo copista de saber mantenedor do 'atraso', nas diferentes realidades e ante a novas exigências. Algo o movia: a integração latinoamericana e a conquista pelo continente de seu protagonismo histórico. Antecipou, assim, a crítica à modernidade ocidental que, sob a aparência de 'universal', negava aos latino-americanos - não apenas - a capacidade de autointerpretação e de consecução de seus próprios desígnios visando à construção de um cosmopolitismo crítico através da superação do eurocentrismo ${ }^{4}$.

\section{América Latina e geopolítica do conhecimento}

Em fevereiro de 1978, Darcy Ribeiro concedeu uma longa entrevista para o projeto História da Ciência no Brasil. Este projeto, coordenado pelo cientista político brasileiro Simon Schwartzman, realizou, de 1975 a 1978, cerca de setenta e sete entrevistas com intelectuais e cientistas brasileiros de diferentes gerações. Abordava a trajetória e atividades profissionais dos entrevistados, englobando, também, questões sobre o ambiente científico e cultural no país, além da importância e dificuldades do fazer científico no Brasil e no exterior.

Reconhecia-se, na escolha de Darcy Ribeiro como entrevistado, sua destacada posição como etnólogo, antropólogo, educador, criador de universidades, ensaísta e romancista, concomitantemente suas realizações como o Museu do Índio e o protagonismo à frente do Parque Indígena do Xingu. Mencionava-se, também, que elaborou para a Unesco um estudo sobre o Revista Interinstitucional Artes de Educar. Rio de Janeiro, V. 3 N.2 - pag 5-21 (jul/out2017): "Número Esperial Darcy Ribeiro" DOI: 10.12957/riae.2017.31705 
impacto da 'civilização' sobre diversos grupos indígenas brasileiros no século 20, assim como, na colaboração para com a Organização Internacional do Trabalho, a preparação de um manual sobre os povos aborígenes de todo o mundo. Ressaltava-se ainda, na ocasião da entrevista, a organização e direção do primeiro curso de Pós-Graduação em Antropologia, e que havia sido professor de Etnologia, na Faculdade Nacional de Filosofia da Universidade do Brasil (RIBEIRO, 2010).

Ao longo da entrevista, Darcy discorreu sobre a Universidade de Brasília (UnB), explicando seu inovador contraste com qualquer outro modelo de universidade existente, seja no Brasil ou no exterior. Definiu a UnB como um projeto de revisão crítica, nos aspectos cultural, epistêmico, científico e intelectual, que servia também para "tentar definir o quê [sic] que a erudição, o saber, a ciência poderiam dar para nós" (RIBEIRO, 2010, p. 27). Preocupava-o a autonomia da produção científica e intelectual brasileira e seu engajamento aos contextos social, político, cultural e econômico brasileiro, postura que permeou toda sua vida e obra. Sobre o ofício intelectual, explicitava sua intransigência:

quem vive a vida inteira refestelado no bem-bom, sem cheirar ou feder para nariz nenhum, no exercício medíocre ou brilhante da função de escriturário, artista ou investigador, pode ser um homem de letras, de artes ou de ciências, mas não será um intelectual do seu povo, do seu tempo (RIBEIRO, 1980, p. 213).

Criticava a inviabilidade da comunidade acadêmica nacional enquanto se comportasse subserviente aos Estados Unidos, Alemanha ou Inglaterra, limitando, por exemplo, os trabalhos realizados no Brasil que, copiando objetos, esquemas de análise e conclusões geridas em outros espaços geopolíticos, não conquistaria sua luz própria uma vez que "sendo um transplante, [a comunidade científica brasileira] era incapaz de ver a problemática interna, e de se interessar pelo que acontecia, realmente, no país" (2010, p. 34). O antropólogo mineiro ora falava da bioquímica no país, ora se remetia ao campo da oftalmologia. Alertava para o fato para ele esdrúxulo de que teríamos, no Brasil, ótimos profissionais, expertises até mesmo nas doenças oculares mais raras estudadas na Europa ou na América do Norte, capazes de descrever minuciosamente cada um destes casos clínicos, entretanto, "não sabem, nem querem saber, e odeiam quem sabe, quantos cegos há no Brasil; por que há cegueira no Brasil; como é que se cura tracoma; se há um jeito melhor de cuidar de tracoma do que suco de cacto, de mandacaru" (RIBEIRO, 2010, p. 13). Para Darcy, era inconcebível pensar que as carências do país enquanto não fossem incorporadas às agendas de pesquisa do Norte fossem subestimadas por nossos próprios investigadores, preocupados com o reconhecimento nas sociedades científicas na Europa ou na América do Norte e indiferentes, salvo honrosas exceções, aos problemas dos povos da América Latina. 
O intento científico de Darcy Ribeiro, em contrapartida, não seguia a via da repetição ou da submissão teórica, recusando-se assim, a reproduzir o que outros já haviam feito antes ${ }^{5}$. Interessava-lhe percorrer outro caminho. Preocupado em compreender e explicar a sociedade brasileira, destacou que no paradigma epistemológico e científico exógeno, tanto o Brasil como a América Latina seriam simplesmente inexplicáveis. À pergunta que se propusera a responder, resumível em: “por que o Brasil ainda não deu certo?” (RIBEIRO, 1995, p. 13), não encontraria resposta adequada se amparado nos velhos quadros analíticos existentes, teorizações oriundas de outros contextos, insensíveis às experiências históricas e aos conhecimentos situados, impotentes, portanto, para a compreensão dos povos que desconheciam, em suas configurações econômicas, culturais e sócio-políticas.

O Processo Civilizatório (1997), publicado pela primeira vez por Darcy Ribeiro, no exílio uruguaio no ano de 1968 é coerente com a busca de seu autor em legitimar a América Latina como lugar legítimo à produção de teoria. Em sua apresentação, Anísio Teixeira avalia-o como fecundo e de extensa originalidade. Recomenda-o em sua ambição de uma reescrita da história mundial a rechaçar lapsos contidos nos modelos construídos anteriormente. No entanto, chama a atenção para "o fato de havê-lo concebido um homem do Terceiro Mundo [o que] tem, sem dúvida, consequências" (TEIXEIRA, 1997, p. 13). Anísio ressalta tratar-se Darcy Ribeiro do intelectual, dentre todos aqueles inscritos na condição denominada Terceiro Mundo, a apresentar a inteligência mais autônoma de que teve conhecimento, sendo impossível nele identificar "nada da clássica subordinação mental do subdesenvolvimento" (TEIXEIRA, 1997, p. 13).

$\mathrm{O}$ aspecto mais paradoxal de certa falta intrínseca de autonomia da inteligência do subdesenvolvimento está na consciência demasiado lúcida do subdesenvolvimento: isso leva o "subdesenvolvimento" a considerar "presunçoso", "ridículo", levar-se "muito" a sério. Como esse traço se confunde muito com humildade intelectual, que é um traço de autonomia, nem sempre é fácil distingui-lo. Por vezes, ele se revela até entre os mais raramente inteligentes. Em Lobato, acho que se pode lobregar vestígios desse traço. Costumo dizer que Lobato tinha certo pudor do seu país, preferindo manifestá-lo como vergonha de si mesmo. Dava então às coisas mais sérias que dizia um tom de brincadeira, se não de "pilhéria", e, quando resolveu fazer mesmo a sua obra, fê-la para as crianças, deixando para os adultos o seu riso e o seu sarcasmo ... (TEIXEIRA, 1997, p. 14).

Darcy Ribeiro reapresentava o processo civilizatório mundial e suas etapas da evolução sociocultural rompendo com a concepção eurocentrada vigente até aquele momento. Expõe uma 'história alternativa da humanidade' que abre novas possibilidades de compreensão do desenvolvimento histórico. Somado a isto, superando o "consensualismo moderno do centro", 
segundo as palavras do filósofo argentino Enrique Dussel (1977, p. 176), crítico contundente do eurocentrismo, a obra darcyniana irrompe uma antropologia descentralizada e intercultural, passando a incluir as diversidades até então invisibilizadas das Américas, da Ásia e da África.

Propõe os conceitos inovadores de 'modernização reflexa' ('atualização histórica') e de 'aceleração evolutiva', que o autoriza ao diagnóstico de que o subdesenvolvimento não é determinado por causas atávicas, mas “a posição em que se encontra uma sociedade não corresponde a qualidades inatas ou a qualidades imutáveis de sua cultura, senão, em larga medida, a circunstâncias susceptíveis de transformação" (RIBEIRO, 1997, p.135). No exame dos processos civilizatórios, o antropólogo atenta para os distintos modos de produção, sob a inspiração do método marxista, bem como para os conteúdos ideológicos das relações de dominação existentes em cada um deles, que deflagraram, a exemplo dos casos do colonialismo e do imperialismo, os conflitos a as guerras de conquista de territórios. Como desdobramento, observa os processos de deculturação e os neocolonialismos persistentes nas ex-colônias de exploração que são mantidas numa inserção subordinada, como 'povos atrasados' na ordem internacional, como reflexos opacos do desenvolvimento de seus ex-colonizadores. Tais nações experimentam a referida modernização reflexa, por conseguinte, que implica a perda de sua autonomia mediante os processos adaptativos. A estas é vetada a 'aceleração evolutiva', que traduziria o verdadeiro desenvolvimento destas sociedades a ocorrer quando estas "experimentam uma revolução tecnológica com base em sua própria criatividade, ou na adoção completa e autárquica de inovações tecnológicas alcançadas por outras sociedades, ou, ainda, com base em ambas as fontes" (RIBEIRO, 1997, p.70).

Darcy Ribeiro (1997) é leitor de Frantz Fanon que o ajuda a compreender a importância da criação da 'exterioridade' 6 , vital na ruptura com a 'coisificação' do colonizado, sua subalternização e desumanização. Para o intelectual, militante e psiquiatra martiniquense, a imposição colonizadora dilatou uma violência não somente no espaço sócio-político, mas também na mente do colonizado - ou, em suas palavras, de Os condenados da terra (2005) -, gerando sequelas histórico-culturais e epistêmicas multidimensionais. Assim, para que se possa avançar e se elevar a um nível distinto de percepção daquele imposto pelo europeu, é necessária uma 'consciência inventiva' voltada para a descoberta autônoma. Por isso, Fanon é incisivo: “a descolonização é verdadeiramente a criação de homens novos". Tal criação não precisa da legitimação da hegemonia, ao contrário, é legítima "no processo mesmo pelo qual se liberta" (FANON, 2005, p. 53).

Fanon não subestima a Europa, afirmando que esta se trata de uma expressão do humano que não tem anterioridade ou superioridade a quaisquer outras. É significativo que tanto para Revista Interinstitucional Artes de Educar. Rio de Janeiro, V. 3 N.2 - pag 5-21 (jul/out2017): "Número Esperial Darcy Ribeiro" DOI: $10.12957 /$ riae.2017.31705 
Frantz Fanon quanto para Darcy Ribeiro caiba aos povos não-europeus assumir seu lugar como povos e nações 'entre' povos e nações; como homens e mulheres 'entre' homens e mulheres. Nesse sentido, recordamos o filósofo mexicano, Leopoldo Zea (2005, p. 467): é “como um homem, exigindo para si mesmo o que o colonizador exigiu para ele, considerando-se como homem. Não mais, nem tampouco menos".

A descolonização, realmente, é criação de homens novos [...]. Este processo inclui não só o enfrentamento, mas o resultado do mesmo, isto é, a dupla consciência da qual falamos aqui: o colonizado toma consciência da sua humanidade, ao mesmo tempo em que o colonizador toma de sua inumanidade. Um sente que se eleva ao nível de homem, enquanto que o outro sente que como seu ato vai rebaixando o seu nível. Um sente-se impelido a construir um mundo novo, enquanto o outro, a destruir o que criou. Um se vê como uma saída aberta a todas as possibilidades; o outro como uma rua sem saída. O colonizado sentese impelido a continuar sua ação libertadora para passar à criadora; enquanto que o colonizador, como quem reconhece uma culpa, busca apagar esta e começar, se possível, como se nada tivesse feito, partindo do zero. [...] O importante é criar um mundo novo no qual, talvez, queira ou possa incorporar-se o homem ocidental; mas um mundo que não poderá ser o que ele criou ainda que originado de ação subordinadora. Por isso, diz Frantz Fanon, sem rancores, sem ódios: "Pela Europa, por nós mesmos e pela humanidade, companheiros, temos de trocar de pé, desenvolver um pensamento novo, tratar de criar um homem novo". Fazer o que o europeu não foi capaz de fazer, evitar a desumanização na qual caiu o seu humanismo limitado, só assim, diz o filósofo africano, poderemos responder à mesma "esperança dos europeus" (ZEA, 2005, p.471-3. Os colchetes são nossos).

Comungando desta percepção, qualquer colonialidade do conhecimento é recusada por Ribeiro. Conforme ensinou Fanon, diante da submissão intelectual e da subserviência teórica, recomenda-se somente uma postura: "devemos imediatamente detectar e extirpar de nossas terras e de nossos cérebros" (FANON, 2005, p. 287), noutras palavras, recusar ser cópia pois os colonizadores, obviamente, "saberão fazer [esta cópia de si próprios] melhor do que os mais talentosos de nós" (FANON, 2005, p. 365). A nós importa criar o pensamento descolonizado, um pensamento novo.

Sabemos, porém, que, desta colonialidade, sofrem também os intelectuais das ex-colônias a ponto da autonomia intelectual de Darcy Ribeiro lhes parecer uma heresia. Em contrapartida, Ribeiro foi alvo do respeito de alguns por esta mesma ousadia, a exemplo de Betty Jane Meggers, arqueóloga estadunidense e amiga do casal Darcy e Berta Gleizer Ribeiro. Meggers (1997) foi tradutora da primeira edição em inglês de O Processo Civilizatório e uma de suas principais interlocutoras fora da América Latina assim que o livro nasce. No prefácio que escreveu à referida tradução, apresenta Darcy Ribeiro aos leitores norte-americanos como um intelectual que não está condicionado à tradição político-acadêmica euroamericana e destaca sua exterioridade que 
provoca e interpela o Primeiro Mundo por sua perspectiva autônoma que, a partir de outro lugar, esboça o desenvolvimento cultural da humanidade sob aspectos divergentes. O prefácio de Meggers à obra de Darcy Ribeiro foi sobejamente elogiado pelo próprio, em uma carta redigida a ela em março de 1968:

Você fez um prefácio lindo, inteligente, agudo, subversivo... formidável. E me fez entender coisas. Por exemplo, que a qualidade insólita do nosso pensamento vem da condição de dissents que corresponde, no plano intelectual, à rebeldia dos 'hippies'. Costumo dizer, na minha vaidade, que nós, intelectuais revolucionários somos o novo sal da terra que dá gôsto [sic] e sentido à vida. Tenho de alargar o conceito para reconhecer que os descontentes somos os anunciadores do mundo novo [sic], seja porque não gostamos dêste [sic] e o manifestamos na conduta, seja porque, sendo capazes de prefigurar um mundo melhor, nos tornamos missionários. É o nôvo [sic] salvacionismo que se expande, no corpo do qual só se salvará quem sentir desespêro [sic] ou tiver fé suficiente para se negar ao cinismo e ao conformismo (RIBEIRO, apud. MATTOS, 2007, p. 219).

O empenho epistêmico de Darcy Ribeiro indigna-se contra a sentença de que estaria algum povo 'condenado' a uma interpretação exógena, não lhe sendo facultado pensar a si mesmo. A questão central, porém, como chama atenção Ramón Grosfoguel (2010), é que a mudança do sujeito da fala desafiava o locus da enunciação consagrado para a produção de conhecimento e tendia a desestabilizar a geopolítica do conhecimento. Em outras palavras:

$\mathrm{Na}$ filosofia e nas ciências sociais ocidentais, aquele que fala está sempre escondido, oculto, apagado da análise. A 'ego-política do conhecimento' da filosofia ocidental sempre privilegiou o mito de um 'Ego' não situado. O lugar epistêmico étnico-racial/sexual/de gênero e o sujeito enunciador encontram-se, sempre, desvinculados. Ao quebrar a ligação entre o sujeito da enunciação e o lugar epistêmico étnico-racial/sexual/de gênero, a filosofia e as ciências ocidentais conseguem gerar um mito sobre um conhecimento universal verdadeiro que encobre, isto é, que oculta não só aquele que fala como também o lugar epistêmico geopolítico e corpo-político das estruturas de poder/conhecimento colonial, a partir do qual o sujeito se pronuncia (GROSFOGUEL, 2010, p. 459).

A expressão 'giro descolonial', mais usual hoje, remete-se à explicitação e à reversão de tal invisibilidade. Podemos entendê-la como uma inflexão epistêmica, ética e política nas ciências sociais latino-americanas que insere na construção do conhecimento a herança do colonialismo a fim de problematizá-la. De longa data é o empenho latino-americano para a compreensão da herança colonial, das resistências e lutas dos grupos subalternizados, bem como para o desvendamento dos mecanismos do capitalismo dependente através da crítica contundente ao eurocentrismo e, mais recentemente, ao imperialismo do Norte. No fim dos anos 1990, alguns 
estudiosos mantêm encontros com certa regularidade que os leva se configurar como um grupo nomeado 'modernidade/colonialidade', contestando as matrizes epistêmicas hegemônicas de produção de conhecimento que naturalizam categorias incapazes de dar inteligibilidade às experiências sócio-econômica-históricas que não se contentam em ser tomadas como réplicas daquelas típicas dos contextos modernos euro-setentrionais. Deste grupo participam, dentre outros, além dos já citados Dussel (Argentina/México) e Grosfoguel (Porto Rico/EUA), também, Aníbal Quijano (Peru), Walter Mignolo (Argentina/EUA), Santiago Castro-Gómez (Colômbia), Nelson Maldonado-Torres (Porto Rico/EUA), Edgardo Lander (Venezuela), Arturo Escobar (Colômbia) e Catherine Walsh (EUA/Equador).

Oriundos de distintos campos disciplinares e tradições intelectuais, o grupo converge na percepção da inexistência do conhecimento neutro e universal, chamando tal mito de 'retórica de poder' e desacreditando no discurso epistemológico hegemônico da ciência e da filosofia que propõe o saber científico 'des-localizado', 'des-contextualizado' e 'des-incoporado', abstrato e transcendental, pairando sobre as contingências e seus sujeitos históricos (CRUZ, 2017, p. 26). O movimento intelectual descolonial expõe que nada há de inocente na inclinação, bastante presente e frequente no continente latino-americano - como se fosse 'natural' - em se desconhecer os autores e as correntes teóricas formuladas a partir de nosso próprio contexto, nas línguas aqui faladas.

Olhamos o mundo pelas lentes de autores que construíram suas reflexões, em muitos casos, referenciados em realidades completamente alheias às nossas. No entanto, ignoramos os intelectuais que falam a partir dos lugares, experiências e línguas do sul. Não é raro intelectuais brasileiros ignorarem solenemente a produção intelectual dos países vizinhos, sem falar do que é produzido nos continentes africano e asiático. A questão não é a limitação ou ignorância [uma condição de todos] e sim a naturalidade com que aceitamos o fato de que o conhecimento legítimo, sofisticado, de vanguarda é atributo somente de certos centros geopolíticos do norte global [são inegavelmente centros devido a todos os recursos e poderes acumulados nesses lugares historicamente] (CRUZ, 2017, p. 28).

Vemos os centros de pesquisa e os cursos em níveis de graduação e de pós-graduação submeterem-se a "um certo colonialismo [que] faz com que leiamos com atenção os europeus ou norte-americanos, mas nunca os latino-americanos" (DUSSEL, 1986, p. 15). Em geral, copiam-se as teorias e sistemas conceituais estrangeiros que são utilizados e ensinados por nossos quadros universitários, os quais possuem, em geral, uma ou mais etapa de formação no exterior, o que lhes propiciou o bom manejo da língua estrangeira e a confiança de que trazem ao Brasil (ou à América Latina) as mais avançadas inovações em seu campo de saber. Podem estar certos, em parte. 
Dificilmente, porém, poderão ou pleitearão ser chamados de intelectuais públicos, comprometidos com o desenvolvimento crítico e autônomo de sua nação, em sua opção de se manter alheios à original produção de pensamento latino-americano, não o fazendo paritariamente dialogar e confrontar as inspirações alhures nos debates acadêmicos.

Podemos afirmar, sem riscos, que Darcy Ribeiro participou do 'giro descolonial' antes mesmo da denominação existir, intentando, ele mesmo, pensar o desigual desenvolvimento dos povos na América Latina, redefinindo uma teoria geral dos processos civilizatórios humanos na qual outros futuros, que não exclusivamente a modernidade euro-setentrional, pudessem ser imaginados numa perspectiva evolucionista multilinear, em que novos modos de produção e seus conteúdos ideológicos pudessem ser mapeados em sua diversidade, coetaneidade e mútua dependência. Pensar, contudo, uma perspectiva emancipatória a partir da América negra, indígena, mestiça e de seus segmentos excluídos significa deslocar os loci de enunciação para as margens e periferias, o que se traduz numa política da epistemologia, ao qual também se dedicou Darcy Ribeiro.

\section{Considerações Finais}

Darcy Ribeiro inaugurou seus 30 anos de produção escrita com $O$ processo civilizatório. Etapas da evolução sócio-cultural (1997[1ª . Ed. 1968]) e As Américas e a Civilização. Processos de formação e causas do desenvolvimento desigual dos povos americanos (2007[1 ${ }^{\text {a }}$. Ed. 1969]). Seguiram-se Os índios e a civilização. A integração das populações indígenas no Brasil moderno (1996 [1ª . Ed. 1970]); O dilema da América Latina (1988 [1ª. Ed. 1971]); Os brasileiros - teoria do Brasil (1978 [1 ${ }^{\text {a }}$. Ed. 1978]); e, por último, O povo brasileiro. A formação e o sentido do Brasil (1995 [1ª . Ed. 1995]).

Desenvolveu, assim, sua original 'antropologia dialética', atualizando, sem falsa modéstia, o materialismo histórico e dialético, revisou o evolucionismo, apostou na multilinearidade e, introduzindo as leituras latino-americanistas, estudou as sucessões de diferentes revoluções tecnológicas e processos civilizatórios por meio dos quais da condição de coletores e caçadores a humanidade se reinventou em novos modos de produção. Atentou para o enriquecimento tecnológico, mas também para as experiências sociais, saberes, crenças e valores. Não supôs, de modo algum, uma hierarquia de culturas e jamais imaginou que o modo que sucedia o anterior seria, por isso, nalgum sentido superior. Conseguiu, contudo, sistematizar 10.000 anos de história da humanidade, desta vez, incluindo os povos ibéricos, latino-americanos, africanos, excluídos de tratados de teóricos outros. 
Dentre outros postulados, o estudioso recusou o atributo de universalidade ao intercurso ‘escravismo-feudalismo-capitalismo' que evidenciou como uma sucessão do processo histórico específica à formação europeia. Reagia à reconstrução analítica do desenvolvimento formativo dos povos do mundo extra-europeu mediante o uso acrítico de categorias temporais e situadas que pretendiam explicar por um único modelo falsamente trans-histórico a diversidade humana, invisibilizando-a. Assim, propugnou que a América Latina ainda viesse a existir como uma articulação de povos 'estruturados' para si mesmos, portadores de um projeto de desenvolvimento autônomo e auto-sustentado, contra qualquer imposição 'recolonizadora'. Falava de um 'universal antagônico' ao eurocentrismo, porque ampliado, aberto a novas histórias, híbrido e mais enriquecido. Seu pensamento coaduna com o do crítico literário brasileiro Silviano Santiago:

A maior contribuição da América Latina para a cultura ocidental vem da destruição sistemática dos conceitos de unidade e de pureza: estes dois conceitos perdem o contorno exato de seu significado, perdem seu peso esmagador, seu sinal de superioridade cultural, à medida que o trabalho de contaminação dos latino-americanos se afirma, se mostra mais e mais eficaz. A América Latina institui seu lugar no mapa da civilização ocidental, graças ao movimento de desvio da norma, ativo e destruidor, que transfigura os elementos feitos e imutáveis que os europeus exportavam para o Novo Mundo (SANTIAGO, 2006, p. 16).

Na recepção das ideias-força de Pátria Grande e Nuestra América, respectivamente, de Simon Bolívar e de José Martí (MIGLIEVICH-RIBEIRO; ROMERA JR., 2015), a utopia darcyniana apostava que a América Latina ainda se anunciasse ao mundo como uma sociedade de outro tipo, não mais servil aos antigos e novos colonizadores, também não reprodutora de seus mecanismos de dominação do Outro. Darcy Ribeiro desestabilizou narrativas e confrontou os cânones. Explicou que o 'atraso' impingido aos povos latino-americanos nascia "como fator contingencial, e não como uma etapa ou apenas um estado 'atrasado' em contraposição a modelos avançados de sociedade" (MATTOS, 2007, p. 135). Aqui, o atraso não se apresentava como antípoda da modernidade, mas era seu coetâneo, produzido por ela, uma modernidade exógena, imposta, negadora da integridade étnica das populações da América Latina e de sua autodeterminação.

Sua perspectiva sócio-antropológica foi, também, diretriz de seus 'fazimentos', no respeito profundo ao 'fenômeno humano' que haveria de ser a marca da mais íntegra antropologia, atenta às experiências sociais, diversas e articuladas, plurais e interculturais, de direções sempre imprevisíveis. 
1 Após a derrota da Revolução Constitucionalista de 1932, São Paulo se reerguia e, para tal, apostava na criação de novas universidades. Neste tempo, as ciências sociais ganhavam prestígio em seu papel possível no planejamento econômico e desenvolvimento social. Foi fundada, em 1933, a Escola Livre de Sociologia e Política - sob ascendência norte-americana e especial inspiração nos estudos urbanos e rurais da Escola de Chicago, uma sociologia empírica, de cunho reformista - que contratou os sociólogos e antropólogos estrangeiros a exemplo de Horace Davis, Samuel Lowrie, Donald Pierson, Radcliffe-Brown, além dos visitantes Franklin Frazier, Melville Herskovits, Charles Wagley. O bacharelado em Ciências Sociais e Políticas tinha a duração de 3 (três) anos (Cf. MAIO, 2010, p. 29-30).

${ }^{2}$ Destes, alunos e ex-alunos da FNFi se faziam presentes, a exemplo de Klaas Woortmann, Mary Woortmann, Alzira Abreu, Maria Luiza Proença. Os projetos do CBPE, financiados pelo MEC em parceria com a Unesco e, também, com a USP, promoveram trabalhos comuns entre Florestan Fernandes, Oracy Nogueira, Eduardo Galvão e Costa Pinto. À época, cabe mencionar que Darcy Ribeiro era, também, professor catedrático na Faculdade Nacional de Filosofia (FNFi/UB) à frente da disciplina Etnografia Brasileira e Língua Tupi (Cf. MIGLIEVICH-RIBEIRO, 2015).

${ }^{3}$ Cf. MiGLIEVICH-RIBEIRO, A. M., 2017.

${ }^{4}$ Dussel refere-se ao mito do eurocentrismo, ou seja, à miragem de se pensar a Europa como o centro da história mundial e topo da civilização em vários de seus escritos, dentre eles, podem ser consultados: 1492 o encobrimento do outro: a origem do mito da modernidade (1993); Más allá del eurocentrismo: el sistema-mundo y los limites de la modernidade (1999); Eurocentrismo y modernidade (2001); Philosophy of liberation, the postmodern debate, and Latin American Studies (2008); Meditações anticartesianas sobre a origem do antidiscurso filosófico da modernidade (2010).

${ }^{5}$ Em exemplo, como o próprio Darcy conta em O Povo Brasileiro, que começou a redigir na década de $1950-$ efetivamente publicada somente em 1995 -, e que objetivou ser uma síntese interpretativa capaz de retratar o Brasil em sua integralidade e complexidade, tal projeto foi interrompido diversas vezes em razão de outras tarefas de modo que foi retomá-lo somente em seu período de exílio, no Uruguai, como resultado de extensa pesquisa elaborada sobre o Brasil e América Latina na Biblioteca Nacional de Montevidéu, no entanto: "uma vez completado o livro, a primeira leitura crítica que consegui fazer dele todo me assustou [afirmou Darcy]: não dizia nada, ou pouco dizia que não tivesse sido dito antes" (RIBEIRO, 1995, p. 13). O que fez com que Darcy reelaborasse a partir de então, todo seu projeto e empenho epistêmico. A obra é conhecida por ter sido revisada e, enfim, acabada já seu autor bastante fragilizado pelo câncer, em seu refúgio, na praia de Maricá, no estado do Rio de Janeiro.

${ }^{6}$ A categoria exterioridade "quer indicar o âmbito onde o outro homem, como livre e incondicionado por meu sistema e não como parte de meu mundo, se revela" (DUSSEL, 1977, p. 47). Noutros termos, a face de um homem e de uma mulher se revela como outro quando se configura em um sistema de instrumentos como exterior, como um ser humano, e não um mero ente ou coisas que se apresentam no mundo. Apenas exercendo uma liberdade que interpela, que impacta, que provoca, é que a alteridade surge como alguém que é capaz de resistir à totalização instrumental. Já não é um ente que se revela parte de um sistema, não é uma coisa ou algo, é mais, é alguém.

\section{Referências}

BOMFIM, Manoel. América Latina. Males de origem. Rio de Janeiro: Topbooks, 1993.

CORREA, Mariza. A revolução dos normalistas. Cadernos de Pesquisa, n. 66, p. 13-24, 1988a. Traficantes do excêntrico. Os antropólogos no Brasil dos anos 30 aos anos 60. RBCS, n. 6, fevereiro, p. 1-9, 1988 b.

CRUZ, Valter do Carmo. Geografia e pensamento descolonial: notas sobre um diálogo necessário para a renovação do pensamento crítico. In: CRUZ, Valter do Carmo; OLIVEIRA, Denílson Araújo de Oliveira (org.). Geografia e giro descolonial. Experiências, ideias e horizontes de renovação do pensamento crítico. Rio de Janeiro: Letra Capital, 2017, p. 15-36. 
DUSSEL Enrique. Prefácio. In : ZIMMERMANN, R.. América Latina : o não ser. Petrópolis : Vozes, 1986, p. 13-15.

. Filosofia da libertação na América Latina. São Paulo : Loyola, 1977.

. Meditações anticartesianas sobre a origem do antidiscurso filosófico da modernidade. In : SANTOS, Boaventura S. ; MENESES, Maria Paula. Epistemologias do sul. São Paulo: Cortez, 2010, p. 341-395.

FANON, Frantz. Os condenados da terra. Juiz de Fora : Ed UFJF, 2005.

GOMES, Mércio P.. Darcy Ribeiro. São Paulo: Ícone, 2000.

GROSFOGUEL, Ramón. Para descolonizar os estudos de economia política e os estudos póscoloniais: transmodernidade, pensamento de fronteira colonialidade global. In: SANTOS, Boaventura Sousa; MENESES, Maria Paula (Org.). Epistemologias do Sul. São Paulo: Cortez, 2010, p. 455-491.

GRUPIONE, Luís D. B. ; GRUPIONE, Maria D. F.. Depoimento de Darcy Ribeiro (entrevista). BIB. Boletim Brasileiro de Informação Bibliográfica em Ciências Sociais, n. 44, junh-dez, 1997, p. 3-30.

KANTOR, L.; MACIEL, D. A.; SIMÕES, J. A. (org.). A escola de Sociologia e Política: anos de formação 1933-1953. Depoimentos. São Paulo: Ed. Sociologia e Política, 2009.

LARAIA, Roque. Darcy na Terra Sem Males. O retorno do etnólogo. Ciência Hoje, vol. 21, n. 126, p. 58-59, 1997.

MAIO, Marcos Chor. Apresentação. In: BICUDO, Virginia Leone. Atitudes raciais de pretos e mulatos em São Paulo. Edição organizada por Marcos Chor Maio. São Paulo: Sociologia e Política, 2010.

MATTOS, André L. L. B.. Darcy Ribeiro e a antropologia no Brasil (1944-1956). 26a . Reunião Brasileira de Antropologia, realizada entre os dias 01 e 04 de julho de 2007, Porto Seguro, BA, p. $1-13$.

Disponível em: http://www.abant.org.br/conteudo/ANAIS/CD Virtual 26 RBA/grupo de trabalho/trabalhos/G T\%2015/andre\%20luis\%lopes\%20borges\%20de\%mattos.pdf. Acesso em 31 de maio de 2016. Acesso em: 16 de outubro de 2015.

MEGGERS, Betty Jane. Ecología y biogeografia de la Amazonía. Quito: Ed. Abya-Yala, 1999.

MIGLIEVICH-RIBEIRO, Adelia Maria. Darcy Ribeiro e UnB: intelectuais, projeto e missão. Ensaio: Avaliação e Políticas Púbicas em Educação, vol.25, n.96, p.585-608, jun-2017. Disponível em: http://dx.doi.org/10.1590/s0104-40362017002500939. Acesso em: 22 de julho de 2017.

. Heloísa Alberto Torres e Marina de Vasconcellos. Pioneiras na formação das ciências sociais no Rio de Janeiro. Rio de Janeiro: EDUFRJ, 2015.

MIGLIEVICH-RIBEIRO, Adelia Maria \& ROMERA JUNIOR, Edison. Vozes dissidentes e modernidades dissonantes na América Latina. Legados e projetos de Bolívar e Martí em Darcy Ribeiro. Civitas. Revista de Ciências Sociais, vol. 15, n. 3, julho-setembro, 2015, p. 403-420. -RI

MIGNOLO, Walter. Descolonización epistêmica y ética: la contribuición de Xavier Albó y Sílvia Rivera Cusiqanqui a la reestructuración de las ciências sociales desde los Andes. Revista Venezuelana de Economía y Ciencias Sociales, vol. 7, n. 3 (Set-dic), p. 175-195, 2001.

MIGNOLO, Walter. Histórias locais/projetos globais. Colonialidade, saberes subalternos e pensamento liminar. Belo Horizonte: Ed. UFMG, 2003. 
NEPOMUCENO, Eric. Apresentação. Um turbilhão chamado Darcy. In: RIBEIRO, Darcy. Crônicas brasileiras. Rio de Janeiro: Desidarata, 2009, p. 11-13.

OLIVEIRA, Lucia Lippi. A sociologia do Guerreiro. Rio de Janeiro: Ed. UFRJ, 1995.

OLIVEIRA, Roberto Cardoso. Darcy foi ser múltiplo. Folha de São Paulo. Caderno Folha Especial, 18 de fevereiro de 1997. Disponível em: http:/www1.folha.uol.com.br/fsp/especial/bio/biodarcy1.htm. Acesso em: 31 de maio de 2016.

. Sobre o pensamento antropológico. Biblioteca Tempo Universitário. Rio de Janeiro: Tempo Brasileiro, 2003.

PORTO-GONÇALVES, Carlos. Apresentação da edição em português. In: LANDER, E. (org.). A colonialidade do saber: eurocentrismo e ciências sociais. Perspectivas latino-americanas. Buenos Aires: Clacso, 2005.

RIBEIRO, Darcy. As Américas e a civilização. Processo de formação e causas do desenvolvimento desigual dos povos americanos. São Paulo: Cia das Letras, 2007.

. Os brasileiros: 1. Teoria do Brasil. Petrópolis: Vozes, 1978.

1988.

. O Dilema da América Latina: estruturas de poder e forças insurgentes. Petrópolis: Vozes,

. Os índios e a civilização. A integração das populações indígenas no Brasil moderno. São Paulo: Cia. das Letras, 1996.

. Minhas peles. In: . O Brasil como problema. Rio de Janeiro: Fundar; Brasília: Edunb, 2010, p. 68-82.

- O papel reservado ao intelectual e à ciência nos países pobres. Encontros com a Civilização Brasileira, vol. 3, n. 25, julho, p. 213-216, 1980. 1995.

. O povo brasileiro: a formação e o sentido do Brasil. São Paulo: Companhia das Letras,

. O processo civilizatório. Etapas da evolução sociocultural. São Paulo: Companhia das Letras, 1997.

. Testemunho. São Paulo: Siciliano, 1990.

SANTIAGO, Silviano. As raizes e o labirinto da América Latina. Rio de Janeiro: Rocco, 2006.

TEIXEIRA, Anísio. Apresentação. In: RIBEIRO, Darcy. O processo civilizatório. Etapas da evolução sociocultural. São Paulo: Companhia das Letras, 1997.

ZEA, Leopoldo. Discurso desde a marginalização e a barbárie seguido de "A filosofia latinoamericana como filosofia pura e simplesmente”. Rio de Janeiro: Garamond, 2005. 